Article

\title{
Application-Ready Expedited MODIS Data for Operational Land Surface Monitoring of Vegetation Condition
}

\author{
Jesslyn F. Brown ${ }^{1, *}$, Daniel Howard ${ }^{2,+}$, Bruce Wylie ${ }^{1,+}$, Aaron Frieze ${ }^{2}$, Lei Ji ${ }^{3}$ \\ and Carolyn Gacke ${ }^{2}$ \\ Received: 20 August 2015; Accepted: 17 November 2015; Published: 3 December 2015 \\ Academic Editors: Jose Moreno, Parth Sarathi Roy and Prasad S. Thenkabail \\ 1 Earth Resources Observation and Science (EROS) Center, U.S. Geological Survey (USGS), \\ 47914 252nd St., Sioux Falls, SD 57198, USA; wylie@usgs.gov \\ 2 Stinger Ghaffarian Technologies, Contractor to USGS EROS, 47914 252nd St., Sioux Falls, SD 57198, USA; \\ dhoward@usgs.gov (D.H.); afriesz@usgs.gov (A.F.); cgacke@usgs.gov (C.G.) \\ 3 Arctic Slope Regional Corporation Federal-InuTeq, Contractor to USGS EROS, \\ 47914 252nd St., Sioux Falls, SD 57198, USA; 1ji@usgs.gov \\ * Correspondence: jfbrown@usgs.gov; Tel.: +1-605-594-6003; Fax: +1-605-594-6529 \\ + These authors contributed equally to this work.
}

\begin{abstract}
Monitoring systems benefit from high temporal frequency image data collected from the Moderate Resolution Imaging Spectroradiometer (MODIS) system. Because of near-daily global coverage, MODIS data are beneficial to applications that require timely information about vegetation condition related to drought, flooding, or fire danger. Rapid satellite data streams in operational applications have clear benefits for monitoring vegetation, especially when information can be delivered as fast as changing surface conditions. An "expedited" processing system called "eMODIS" operated by the U.S. Geological Survey provides rapid MODIS surface reflectance data to operational applications in less than $24 \mathrm{~h}$ offering tailored, consistently-processed information products that complement standard MODIS products. We assessed eMODIS quality and consistency by comparing to standard MODIS data. Only land data with known high quality were analyzed in a central U.S. study area. When compared to standard MODIS (MOD/MYD09Q1), the eMODIS Normalized Difference Vegetation Index (NDVI) maintained a strong, significant relationship to standard MODIS NDVI, whether from morning (Terra) or afternoon (Aqua) orbits. The Aqua eMODIS data were more prone to noise than the Terra data, likely due to differences in the internal cloud mask used in MOD/MYD09Q1 or compositing rules. Post-processing temporal smoothing decreased noise in eMODIS data.
\end{abstract}

Keywords: Moderate Resolution Imaging Spectroradiometer; MODIS; monitoring; hazard; rapid; satellite; remote sensing; Terra; Aqua; Normalized difference vegetation index; NDVI

\section{Introduction}

Data streams from daily or near-daily Earth observing satellite systems such as the Advanced Very High Resolution Radiometer (AVHRR) and the Moderate Resolution Imaging Spectroradiometer (MODIS) have been used for many years to support studies of land disturbance, health of rangelands, croplands, and forests; for tracking drought impacts and vegetation phenology; or monitoring hazards such as forest fires. These satellite data streams in operational applications have clear and significant benefits for monitoring, especially when monitoring products are updated frequently during the life-cycle of the events [1-7]. Although the aforementioned applications may not always 
require observation data to be delivered within seconds, minutes, or hours, there is an obvious advantage to decision-makers when data related to disturbance or hazards are received, processed, and distributed rapidly (i.e., within one to several days). For monitoring fire danger, drought, or cropland health, for example, the value of input data is decreased when is the data are more than just a few days old [1]. Monitoring systems can thus benefit from the relatively high temporal frequency due to the global near-daily overpass of certain satellites. Daily data delivered with low latency are especially beneficial to applications that require rapid monitoring of hazards such as drought, flooding, or wildfire.

From the early 1980s forward, the AVHRR sensor aboard the National Oceanic and Atmospheric Administration (NOAA) series of platforms has delivered a vital, nearly continuous satellite record for terrestrial monitoring. The MODIS instrument (from Terra and Aqua platforms, launched in 2000 and 2002, respectively) has provided substantial improvements to AVHRR for monitoring in spatial resolution, number of spectral channels, choices of bandwidths, radiometric calibration, and science-quality derived products [8]. However, certain standard MODIS land product characteristics hindered its use in operational applications requiring near-real time data. These characteristics, including the Integerized Sinusoidal standard map projection, tiled file format, composite interval, high-latitude enhanced "bow-tie" effects [9], and production latency were identified as challenging by an ad-hoc community of practice [10]. In response to these issues, in 2008 the U.S. Geological Survey (USGS) Earth Resources Observation and Science (EROS) Center developed an alternate expedited MODIS processing capability to serve various monitoring applications (Figure 1). The application-ready composite products from this capability are called "eMODIS composites". The " $\mathrm{e}$ " in eMODIS refers to the expedited processing flow providing useful land observations in less than $24 \mathrm{~h}$. eMODIS products complement the standard National Aeronautics and Space Administration (NASA) Earth Observing System (EOS) MODIS products and provide a consistent daily delivery of vegetation index products within 12-24 h of the most recent satellite overpass. eMODIS products have characteristics designed to feed operational early warning applications including: (1) low latency or rapid delivery; (2) a mosaicked national image format; and (3) a daily delivery of weekly composited observations.

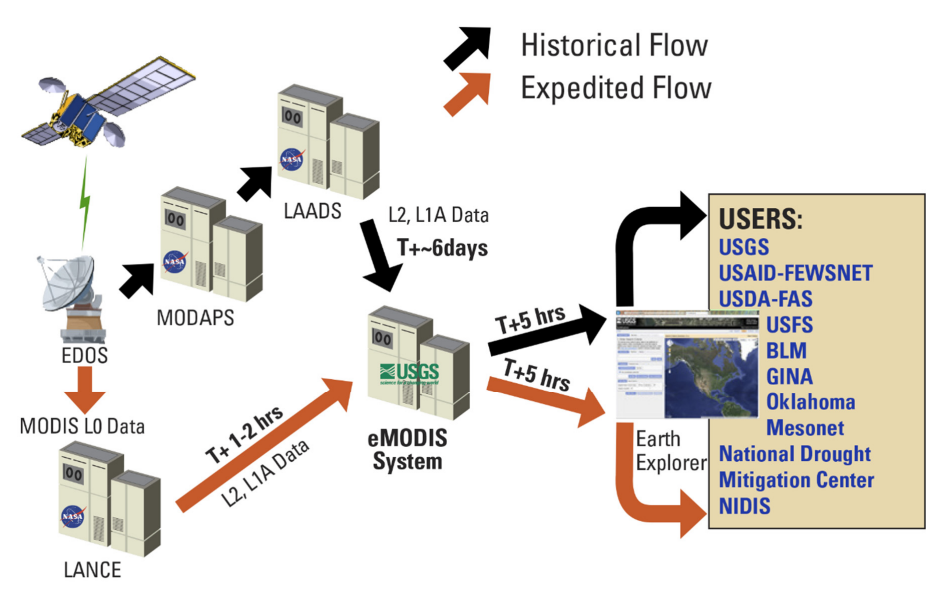

Figure 1. eMODIS data processing stream and selected end users. Acronyms: Earth Observing System (EOS) Data and Operations System (EDOS), Moderate Resolution Imaging Spectroradiometer (MODIS), MODIS Adaptive Processing System (MODAPS), Level 1 and Atmosphere Active and Distribution System (LAADS), Land, Atmosphere Near real-time Capability for EOS (LANCE), U.S. Geological Survey (USGS), U.S. Agency for International Development (USAID), Famine Early Warning Systems Network (FEWS NET), U.S. Department of Agriculture (USDA), Foreign Agriculture Service (FAS), U.S. Forest Service (USFS), Bureau of Land Management (BLM), Geographic Information Network of Alaska (GINA), National Integrated Drought Information System (NIDIS). 
The eMODIS processing flow (Figure 1) ingests MODIS daily Level-2 swath data acquired from two different NASA sources, the Land, Atmosphere Near real-time Capability for EOS (LANCE) and the Level 1 and Atmosphere Archive and Distribution System (LAADS). The processing flow is described in greater detail in Section 2.1. The overarching goal of the eMODIS processing system was to provide application-ready national-to-continental scale composites with no more than a 24-h latency (i.e., near real time or NRT) for operational monitoring applications (Table 1). The usual delivery of standard MODIS products is between 6 to 10 days after data collection. The heritage for the eMODIS production for the contiguous U.S. and Alaska dates back to the early 1990s in the USGS EROS Conterminous U.S. (CONUS) AVHRR Greenness data production (https://lta.cr.usgs.gov/NDVI/) [11].

Table 1. Selected product differences for standard Moderate Resolution Imaging Radiometer (MODIS) and expedited MODIS (eMODIS) Normalized Difference Vegetation Index (NDVI) products.

\begin{tabular}{lll}
\hline Characteristics & Standard MODIS & eMODIS \\
\hline Product Latency & 6-10 days & 6-10 h \\
\hline Image Geometric Processing & $\begin{array}{l}\text { Sinusoidal grid, requires } \\
\text { resampling, reprojection }\end{array}$ & $\begin{array}{l}\text { Single resampling, } \\
\text { directly from swath }\end{array}$ \\
\hline Coverage & Tiled coverage & $\begin{array}{l}\text { Tailored map coverage } \\
\text { (national or continental) }\end{array}$ \\
\hline Composite Interval & 16-day composite periods & 7-day composite period \\
\hline Format & HDF-EOS & Geotiff \\
\hline
\end{tabular}

\section{Objectives}

The objectives of this study are to highlight and clarify the differences and similarities between standard MODIS and eMODIS data sets with a geographic focus on CONUS. Prior studies have compared and evaluated various MODIS products for Alaska including eMODIS and standard MODIS [12,13]. The study by Ji et al. (2010) showed that 250 m-resolution eMODIS Alaska NDVI data had significantly improved geometric features over standard MODIS data, while retaining the original MODIS radiometric characteristics. More cloudy data were identified in eMODIS 7-day composites as compared to standard MODIS 16-day (MOD/MYD13A2) products [13] and probably were related to a lower probability of finding a cloud-free observation over a shorter time span.

Other eMODIS application-ready data products for international regions are regularly produced to support the Famine Early Warning Systems Network (FEWS NET) and have similar processing flows to what is described below, although there are differences in the number of daily observations included in the composites and the image domains and projections (e.g., Africa, Central America, and Asia). FEWS NET produces low latency image products from eMODIS that are posted online for users (http://earlywarning.usgs.gov/fews/). These international eMODIS products were not evaluated in the current study. However, a consistent eMODIS processing data flow is used for all eMODIS products, and therefore, we expect the same level of consistency in all eMODIS products as compared to standard MODIS.

Rapid or near-real time data production streams and resulting products for operational use can vary from standard science-level products as the quick processing time may prevent the ingest of particular ancillary inputs. A report issued by the USGS in 2010 [10] described the eMODIS processing flow in detail; however, subsequent changes have been implemented into the system. This paper provides documentation for the current status of the eMODIS processing system, especially as it pertains to the conterminous U.S. data stream. Other existing eMODIS data streams (e.g., FEWS NET, Alaska) have unique characteristics (image domains, repeat schedule, and composite length in days) that have been tuned to specific user requirements of those data. 


\section{Materials and Methods}

\section{1. eMODIS NDVI Composites: Input Data, Processing, and Data Products}

eMODIS products are generated by computing NDVI from standard EOS surface reflectance [14] (http://modis-sr.ltdri.org/) from both Terra and Aqua MODIS instruments. The eMODIS processing system runs on Linux hardware and utilizes code written in Perl and $C$ programming languages. eMODIS employs the NASA LANCE (http://lance.nasa.gov/) data portal as the source for swath input data for expedited production and the NASA LAADS (http://ladsweb.nascom.nasa.gov/) as the source for historical production. Both sources provide the surface reflectance, geolocation, and cloud mask files needed to create eMODIS composites as shown in Table 2. LANCE data are delivered in near real-time (typically less than $3 \mathrm{~h}$ ) using predicted ancillary data, while LAADS data have been processed with precision inputs available after spacecraft location and climatology have been calculated. The eMODIS composite products calculated from LANCE swath input data are typically staged for users between 6 to $12 \mathrm{~h}$ after the last daily input acquisition.

Table 2. Input data for expedited Moderate Resolution Imaging Spectroradiometer (eMODIS) composites. Note: In the product names, MOD refers to Terra MODIS and MYD refers to Aqua MODIS.

\begin{tabular}{lcc}
\hline Input Products & Product Name & Collection Version \\
\hline $\begin{array}{l}\text { MODIS/Terra or Aqua Surface } \\
\text { Reflectance 5-Min L2 Swath }\end{array}$ & MOD09_L2 or MYD09_L2 & 5 \\
$\begin{array}{l}\text { MODIS/Terra or Aqua Geolocation } \\
\text { Fields 5-Min L1A Swath 1 km }\end{array}$ & MOD03_L1A or MYD03_L1A & 5 \\
$\begin{array}{l}\text { MODIS/Terra or Aqua Cloud Mask and Spectral } \\
\text { Test Results 5-Min L2 Swath 250 m and 1 km }\end{array}$ & MOD35_L2 or MYD35_L2 & 5 \\
\hline
\end{tabular}

The eMODIS process that builds separate Aqua and Terra composite products begins with the relevant swath-based surface reflectance, geolocation and cloud mask files. The beginning step strips off the 150,000-m of data from the east and west borders of the swath, eliminating the most off-nadir pixels that are likely to cause the "bow-tie effect" [9]. This step effectively strips swath data with sensor view angles greater than $41^{\circ}$ from nadir. Observations that have along-track pixel sizes greater than $1385 \mathrm{~m}, 692 \mathrm{~m}$, and $346 \mathrm{~m}$ and along-scan pixel sizes greater than $2002 \mathrm{~m}, 1011 \mathrm{~m}$, and $506 \mathrm{~m}$ are removed at the $1000 \mathrm{~m}, 500 \mathrm{~m}$, and $250 \mathrm{~m}$ product resolutions. The algorithm then places the swath data into the spatial domain (e.g., conterminous U.S. grid) using a nearest neighbor resampling method. The gridding algorithm in eMODIS is supported by the General Cartographic Transformation Package (GCTP) library. The GCTP conventions are also used for storing projection information in HDF-EOS swath data files.

A simple NDVI calculation based on MODIS swath Band 1 (red) and Band 2 (near infrared) data is performed for each gridded surface reflectance swath file following Formula (1) where $\rho_{\text {NIR }}$ equals the surface reflectance value in the near infrared band and $\rho_{\text {red }}$ equals the surface reflectance value in the red band.

$$
\mathrm{NDVI}=\left(\rho_{\mathrm{NIR}}-\rho_{\text {red }}\right) /\left(\rho_{\mathrm{NIR}}+\rho_{\text {red }}\right)
$$

The resulting gridded daily NDVI data files representing all available coverage are input into an enhanced maximum value composite (MVC) algorithm. A traditional MVC would be populated by using the highest NDVI value chosen from all available swath data for each pixel in the composite period. Additional image information (e.g., band quality, negative surface reflectance, cloud mask, snow cover, view angle, and sun angle) are consulted in the selection of the NDVI value retained in the eMODIS composites. 
The enhanced MVC algorithm uses a multi-step process to filter through input swath surface reflectance with bad quality, negative values, clouds, snow cover, low view angles, or low sun angles, as follows:

The band quality information in the level-2 surface reflectance data (MOD09 or MYD09) is used to determine pixel quality. Only the pixels labelled "ideal quality" in the "250 m Reflectance Band Quality" layer are used.

1. The band quality information in the level-2 surface reflectance data (MOD09 or MYD09) is used to determine pixel quality. Only the pixels labelled "ideal quality" in the "250 m Reflectance Band Quality" layer are used.

2. Observations with negative surface reflectance values are assigned an exclusion flag to remove them from the compositing process. Pixels with no positive values during the product interval are filled using a second pass that retrieves a negative reflectance as best available.

3. The solar zenith angle is acquired from the $1000 \mathrm{~m}$ geolocation input file (MOD03 or MYD03). Any pixels acquired at sun angles greater than $83^{\circ}$ are eliminated as composite candidates.

4. The cloud mask input file (MOD35_L2 or MYD35_L2) is used to minimize the overall presence of cloudy observations in the composite product. The first three bits in the first byte (band) of the "Cloud Mask and Spectral Test Results" layer are used for general cloud assessment based on whether or not the pixel's cloud state was determined, and whether a determined state was clear or cloudy. The preferred selection is a pixel labeled as "Determined" and "Probably Clear" or "Confident Clear".

5. If an observation was "Not determined," or is "Determined" but "Cloudy" or "Uncertain," then it is treated as cloudy. If there were no clear pixels available in the seven-day record, the pixel from the latest acquisition was used, regardless of its cloud state. Having determined which pixels were of ideal quality, contained positive reflectance values, were acquired at acceptable sun angles, and were cloud-free, the filtering process selected the two pixels containing the highest (maximum) NDVI values. The next step checked the two remaining pixels for snow cover, which is read from the sixth bit in the first byte in the cloud mask input file. If one of the two highest NDVI observations was flagged as snowy, it was eliminated from the selection process and the single remaining pixel was used in the final composite. If neither or both values were snowy, the pixels were examined for their position from nadir.

6. The view angle (distance from nadir) finally determined which observation is used in the composite. The sensor zenith angle taken from the $1000 \mathrm{~m}$ geolocation input file (MOD03 or MYD03) was resampled for the $250 \mathrm{~m}$ and $500 \mathrm{~m}$ products and reviewed to determine which of the remaining observations was closest to nadir view and selected for the final composite.

These steps promote use of the highest quality, most cloud-free, snow-free, nadir-view pixels (up to $41^{\circ}$ view angle) that are available during the period to populate each eMODIS CONUS composite, wherein high NDVI is considered before sensor scan angle. The best available observation is selected for the final composite except in cases when the "best" is snowy, cloudy, or negative. In the worst case, in which all available observations have negative surface reflectance, are cloudy, snow-covered, or have unacceptable view or sun angles, the processing flow will ingest the most recently acquired observation. An eMODIS quality data file that describes pixel status accompanies each composite.

Each pixel in the eMODIS product quality data file contains one of six values describing the state of the final pixel used in the composite. Typically, pixels will carry a " 0 " label, indicating good quality input data, but there are occasions where the best available input pixel contained snow, clouds, or some other condition described above. Based on the eMODIS enhanced MVC algorithm steps, pixels are labeled in the quality file with a number that indicates pixel quality: 0-high quality, 1-cloudy, 2-bad surface reflectance quality, 3-negative surface reflectance, 4-snowy, or 10-fill value. The quality data can be used to subsequently filter data by operational users. 
The eMODIS composites for CONUS are updated on a daily basis (using rolling seven-day periods) and made available at no cost from the USGS (https:/dds.cr.usgs.gov/emodis/). Access to eMODIS data directories is provided via web-based authorization. For security and accountability, the eMODIS data distribution system requires a USGS account and password to download data which is established via the Earth Explorer interface (https://earthexplorer.usgs.gov/register/). In addition, Earth Explorer supports bulk or individual product access to eMODIS data.

\subsection{Standard MODIS (MOD/MYD09) Products: Input Data, Processing, and Data Products}

Standard MODIS surface reflectance (MOD/MYD09) ingests daily level 2 swath data processed through LAADS. The method used to select the observations for the 250-m MODIS reflectance eight-day composite (MOD09Q1) involves a multistep scoring process, however, maximum value NDVI is not one of the criteria. Each observation within the eight-day period is assigned a score based on whether it is flagged for cloud, cloud shadow, high aerosol or low aerosol, or contains high view angle or low solar zenith angle [15]. Scores 0-9 are assigned to the pixel in the composite using the following criteria:

- Score 0: Observation with fill values for data;

- Score 1: Observation with bad data derived from a faulty or poorly corrected L1B pixel;

- Score 2: Observation with high view angle (60 degrees or more);

- Score 3: Observation with high solar zenith angle (85 degrees or more);

- Score 4: Observation flagged as cloudy;

- Score 5: Observation flagged as containing cloud shadow;

- Score 6: Observation flagged as uncorrected;

- Score 7: Observation flagged as containing the default level of aerosols;

- Score 8: Observation flagged as containing the highest level of aerosols; and

- Score 9: Good observation which meets none of the above criteria.

The observation with the highest score and the lowest view angle is then selected for the MOD09Q1 output.

\subsection{Temporal NDVI Filtering}

Successful land change monitoring is reliant on frequent observations where the data variability due to actual change is more significant than any noise present in the data. Raw NDVI observations are known to be noisy. Many phenomena affect the data including atmospheric conditions (e.g., clouds, cloud shadows, aerosols) and variable illumination and viewing geometry typically reducing the NDVI. Monitoring applications usually employ some technique for noise filtering or temporal smoothing to reduce the effect of noise on the signal. Smoothing or filtering the data produces a time-series data stream that is closely, and ideally, statistically related to the original data [16,17].

The smoothing approach applied in this study employs a moving window operating on time-series NDVI observations to calculate a regression line. The window is moved one period at a time, resulting in a family of regression lines associated with each point; this family of lines is then averaged at each point and interpolated between points to provide a continuous temporal NDVI signal. Also, since the factors that cause contamination usually serve to reduce NDVI values, the system applies a weighting factor that favors peak points over sloping or valley points. A final operation assures that all peak NDVI values are retained. The resulting relationship between the smoothed curve and the original data is statistically based [18]. The smoothed data can then be applied to various research and operational activities, such as identifying the presence of invasive species, characterizing phenological events, examining vegetation productivity and carbon flux dynamics, and capturing drought timing and severity [5,16,19-23]. 


\subsection{Study Area}

In order to characterize the eMODIS data across a broad range of ground conditions, we selected a large study area covering four contiguous MODIS tiles (Figure 2). This tile selection (h10v04, h11v04, h09v05, h10v05) contains a broad variety of land cover types and also provides coverage over selected carbon flux towers that will be incorporated into future studies. The study time period, during March through October, 2003 to 2012, covered 10 years of observations in order to sample a variety of vegetation conditions. The growing season was our primary focus since this is the period when vegetation monitoring is most critical and our objective was to select an adequate sample spatially and temporally for statistical comparison. Temporally coincident composite periods were selected for each year of the study. Since the compositing periods of the eMODIS were seven days long to facilitate use by applications requiring a standard weekly input and the MODIS surface reflectance product composites were eight days long, seven or eight composites per year that fully overlapped temporally (with a minimum overlap of seven days) were selected for this comparison. A total of 78 overlapping composite dates were analyzed in the study: eight each from 2003, 2004, 2006, 2007, 2008, 2009, 2011, and 2012; seven each from 2005 and 2010. Supplemental Table S1 shows this complete list of composite dates.

This study evaluated and compared time series NDVI composites from multiple sources:

1. Standard Terra MODIS (STM): Collection 5 MOD09Q1 (Terra Surface Reflectance Bands 1-2 Tile $250 \mathrm{~m} 8$ day) (source: https://lpdaac.usgs.gov/data_access/)

2. Standard Aqua MODIS (SAM): Collection 5 MYD09Q1 (Aqua Surface Reflectance Bands 1-2 Tile $250 \mathrm{~m} 8$ day) (source: https://lpdaac.usgs.gov/data_access/)

3. Terra eMODIS (TeM) $250 \mathrm{~m}$ (source: http://earthexplorer.usgs.gov/)

4. Aqua eMODIS (AeM) $250 \mathrm{~m}$ (source: http:/ / earthexplorer.usgs.gov/)

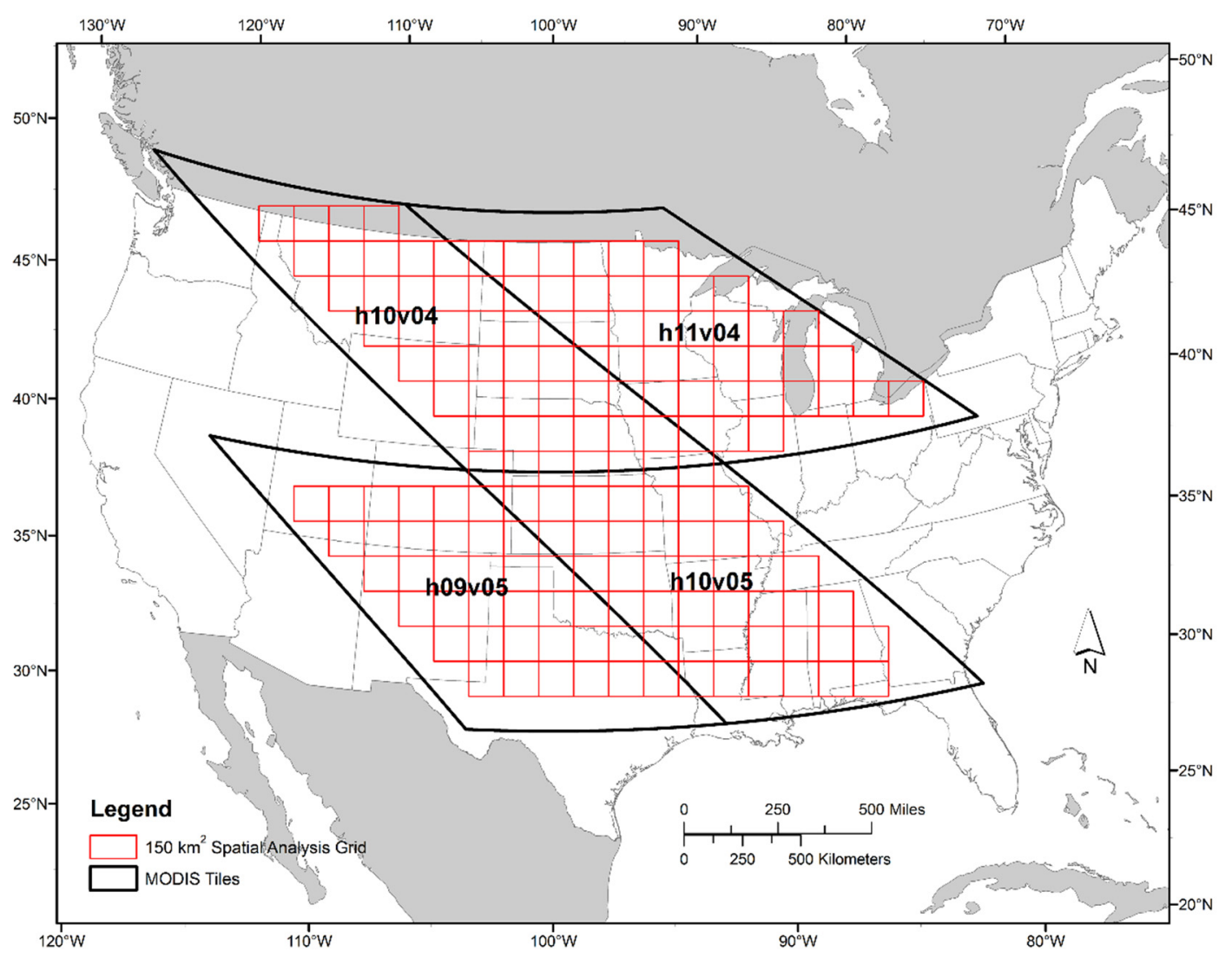

Figure 2. Study area, MODIS tiles, and study zones (in red). 


\subsection{Data Post-Processing}

To assure that the data in this comparison represent similar ground characteristics, multiple masking steps were applied to minimize the impact of low quality, cloudy, water-contaminated, or irrelevant data. Four masks, as shown in Figure 3, were used in the study. They were as follows:

a eMODIS Quality: Only data classified as "good" quality (value $=0$ ) in the eMODIS quality layer were considered in the comparison. All other data quality values were masked out. The source for eMODIS quality data was the quality image file that is bundled with the eMODIS weekly NDVI.

b Standard MODIS Quality: Only data classified as best quality in the MODIS quality layer were considered in the comparison. All other data quality values were masked out. The source for the quality data is the accompanying quality band in the HDFEOS file. Pixels with quality value of " 4096 " were retained and all other quality values were masked.

c Standard MODIS Acquisition Date: Only data acquired during the seven day period where eMODIS and MODIS have temporal overlap were considered in the comparison. The non-concurrent acquisition dates were masked out.

d Water: Only non-water areas were considered in the comparison. All water areas were masked out. The source for the water mask was MOD44W (downloaded from https://lpdaac.usgs.gov/dataset_discovery/modis/modis_products_table/mod44w/).

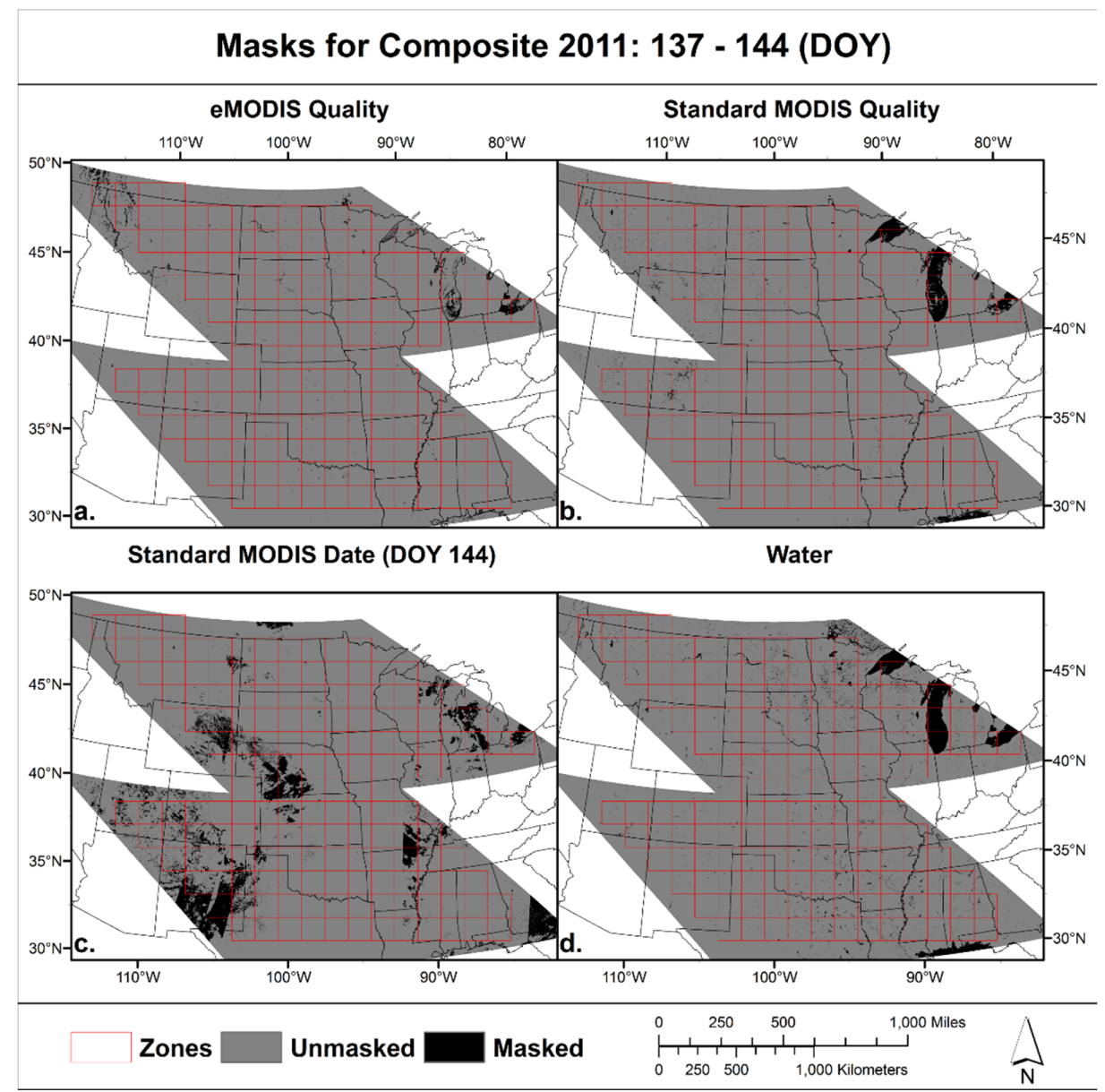

Figure 3. Example composite masks for period (day of year) 137-144 of 2011. (a) eMODIS Quality and Cloud; (b) Standard MODIS Quality; (c) Standard MODIS (eight-day composite) day not included in seven-day composite; and (d) water mask. 
Once all masks were applied, zonal NDVI statistics (e.g., mean, standard deviation, etc.) were calculated for each $150 \mathrm{~km}$ zone shown in red (Figure 2). Per-pixel paired comparisons were not performed for this study; rather we utilized spatial zones for comparison to reduce any impact from data misregistration, to accommodate for data reduction resulting from cloudy or poor quality data masking, and to assure an adequate sample size for the study. The zones were calculated using a fishnet tool in ESRI ArcGIS resulting in 160 zones completely within the four standard MODIS tiles of the study. An earlier study by Ji et al. [12] highlighted the challenges of comparing data that have differing geometric characteristics from source projections requiring subsequent reprojection and resampling steps in order to conduct pixel-to-pixel comparison. Errors introduced by resampling can be significant. However, the prior study demonstrated the geometric fidelity of the eMODIS system for data produced over Alaska [12]. The algorithms for agreement measures, including the Geometric Mean (GM) regression, the Agreement Coefficient (AC), Root Mean Square Deviation (RMDS), Mean Square Difference (MSD), systematic and unsystematic (or random) Mean Product-Difference (MPDs and MPDu) statistics are all found in Ji et al. [12] and were calculated for this study from MODIS zonal data pairs (Standard Aqua, Standard Terra, eMODIS Aqua and eMODIS Terra).

\section{Results and Discussion}

The statistical results of the data comparisons after all masks were applied (Figure 3) to the zonal calculations are shown in Table 3. The AC and $\mathrm{r}^{2}$ results are both strong and very close to 1.0 and to each other in all cases, although the eMODIS (Aqua) vs. eMODIS (Terra) results are slightly lower than Standard Aqua MODIS vs. Standard Terra MODIS. The AC and $\mathrm{r}^{2}$ were nearly identical between Standard MODIS vs. eMODIS (both Aqua and Terra comparisons). The error terms, both systematic and unsystematic or random errors (MSD, MPDs, and MPDu), were all relatively small (less than 0.04) and showed high consistency for the expedited data related to standard MODIS processing. eMODIS (Terra vs. Aqua) showed slightly higher comparative amounts of RMSD, RMPDs, and RMPDu.

Table 3. Statistics and agreement of MODIS NDVI products (2003-2012). For all data pairs, the number of samples was 11,998.

\begin{tabular}{ccccc}
\hline \multicolumn{5}{c}{ Regression and Agreement between Standard MODIS and eMODIS NDVI } \\
\hline Data & $\begin{array}{c}\text { Standard MODIS } \\
\text { vs. eMODIS } \\
\text { (Aqua) }\end{array}$ & $\begin{array}{c}\text { Standard MODIS } \\
\text { vs. eMODIS } \\
\text { (Terra) }\end{array}$ & $\begin{array}{c}\text { Standard MODIS } \\
\text { (Aqua) } \text { vs. Standard } \\
\text { MODIS (Terra) }\end{array}$ & $\begin{array}{c}\text { eMODIS (Aqua) } \\
\text { vs. eMODIS } \\
\text { (Terra) }\end{array}$ \\
\hline GM regression & $a=0.0059 ;$ & $a=0.0124 ;$ & $a=0.0031 ;$ & $a=0.0096 ;$ \\
r & $b=0.9908$ & $b=0.9875$ & $b=1.0010$ & $b=1.0043$ \\
AC & 0.9821 & 0.9829 & 0.9770 & 0.9660 \\
RMSD & 0.9818 & 0.9824 & 0.9770 & 0.9660 \\
RMPD & 0.0252 & 0.0253 & 0.0287 & 0.0351 \\
RMPD $_{\mathbf{u}}$ & 0.0022 & 0.0066 & 0.0026 & 0.0075 \\
\hline
\end{tabular}

Figure 4 shows density scatter plots of the standard MODIS vs. eMODIS zonal data pairs for both Aqua and Terra for all years in the study. Supplemental File S2data.xlsx contains all of the data identified by year. The outliers were rare and mostly minor while Terra outliers were not as extreme as Aqua outliers (i.e., closer to the 1:1 line). The outliers appear to be influenced by increased noise related to increased cloud contamination in the form of sub-pixel clouds that were not effectively screened in the eMODIS processing stream. The increased effect of clouds on data collected in the afternoon (i.e., Aqua) is a likely factor where the 1:30 pm local overpass time coincides with the timing for frequent cloud cover [24]. The so-called " internal cloud mask" used in Standard MODIS (MOD09Q1,MYD09Q1) was not utilized in the eMODIS compositing algorithm and may well have contributed to the differences observed in the quality masks as well as noise remaining in the unmasked pixels in our study [25]. Results from this cloud mask are not made available through 
the LANCE system in a low latency fashion. The pixels retained in this study were considered high quality by both Standard MODIS and eMODIS quality bands, suggesting that the standard MODIS compositing strategy selects daily observations that contain less subpixel noise. To remedy this, the compositing strategy for eMODIS will be reevaluated and potentially changed.

a.

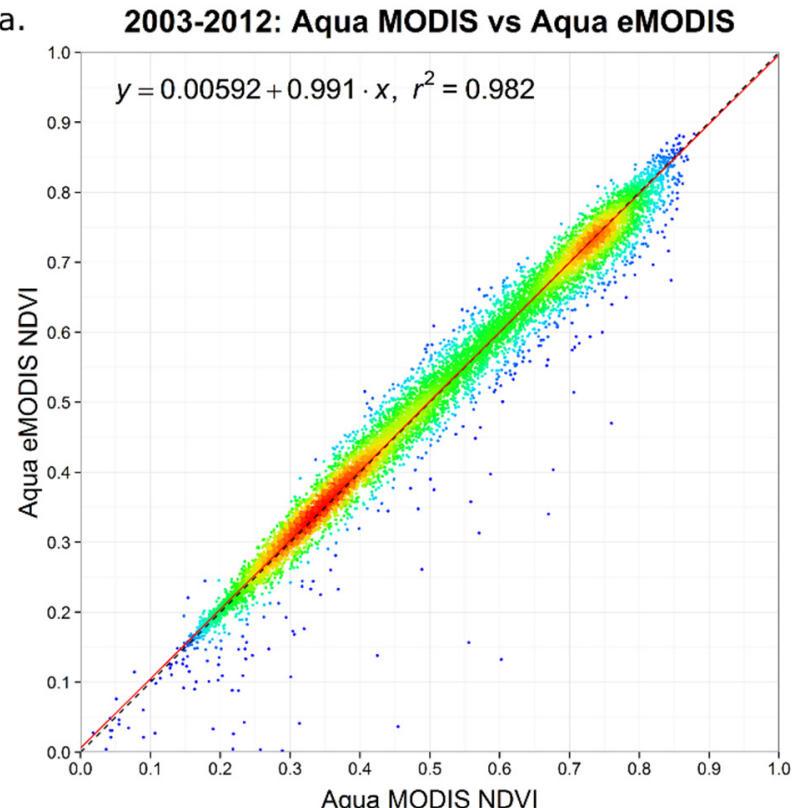

c.

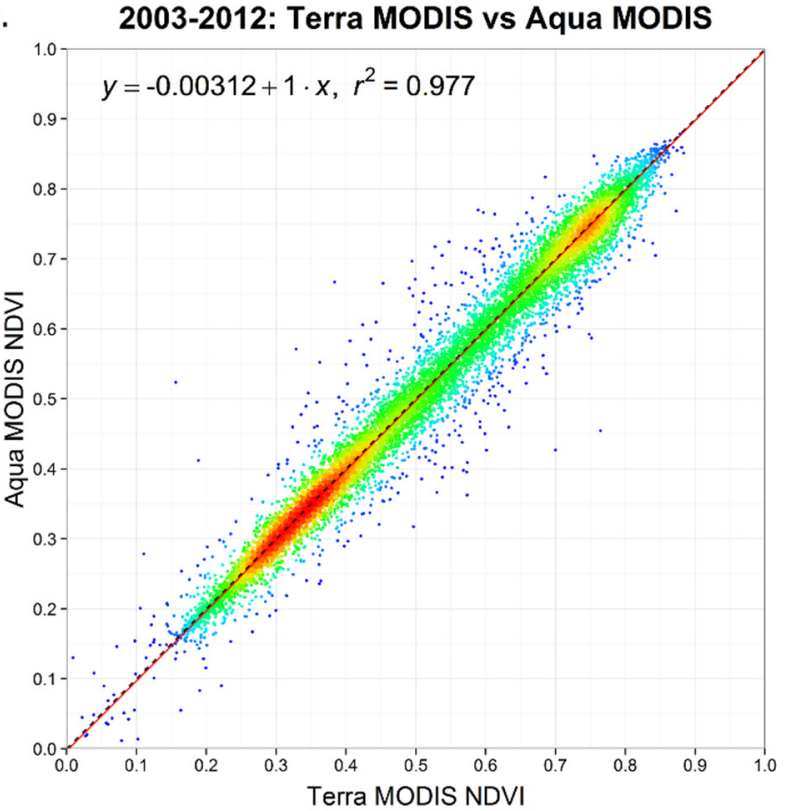

b.

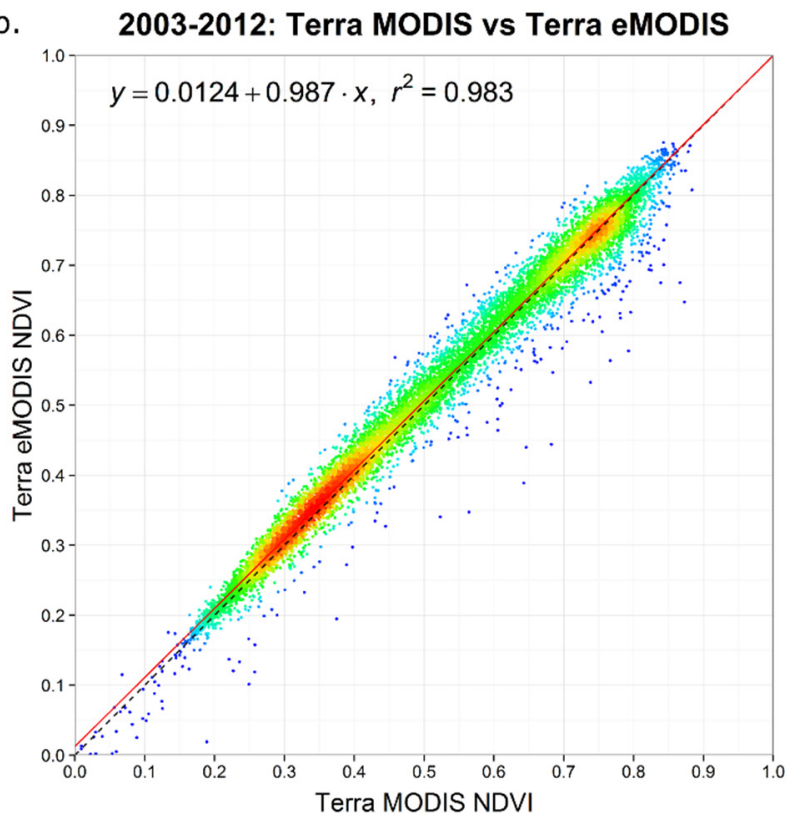

d.

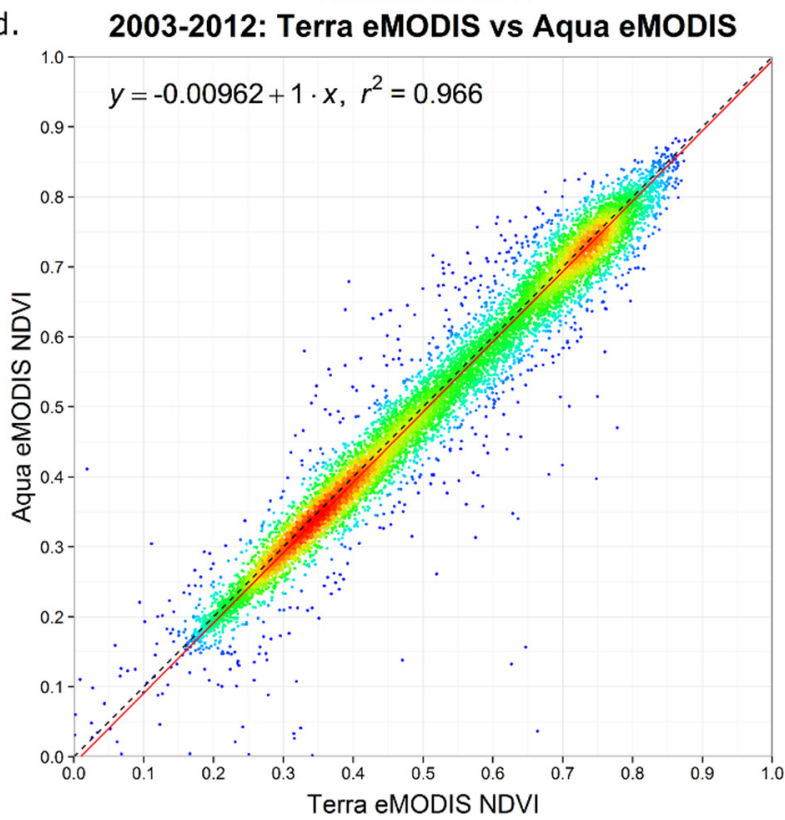

Figure 4. Density NDVI scatter plots, data $(n=11,998)$ for all study zones, 2003-2012. (a) Standard Aqua MODIS vs. Aqua eMODIS; (b) Standard Terra MODIS vs. Terra eMODIS; (c) Standard Terra MODIS vs. Standard Aqua MODIS; (d) Aqua eMODIS vs. Terra eMODIS.

Investigation of outliers showed that they mainly occurred in composite periods that experienced large areas of cloud contamination. Figure 5 shows a close-up of a period especially influenced by clouds (day of year137-144, 2011). Lower eMODIS NDVI compared to Standard MODIS is evident especially surrounding the cloud mask as well as in the southeast of zone 223. Focused analysis on this figure suggests several theories for the root source for eMODIS pixels identified as good quality yet having lower NDVI than what was calculated from MOD/MYD09. 
(1) The eMODIS quality criteria that do not screen "probably clear" daily observations from the MOD35-L2 daily swath data may lead to a composite observation with lower NDVI; (2) The view angle cut off for eMODIS is $41^{\circ}$, but it appears that the cut off for the standard MODIS view angle is $60^{\circ}$. Additional observations with view angles that are screened out of eMODIS but are accepted in a standard MODIS composite may result in a higher NDVI; (3) Standard MODIS compositing includes criteria for aerosols that are not used in the eMODIS compositing process. Further investigation is needed to fully outline this issue, but will need to involve MOD/MYD09 at 500-m resolution.

Although the eMODIS cloud mask that originates from MOD35_L2 or MYD35_L2 was applied as described above, certain pixels were not identified or removed from the comparison using the cloud or other image quality flags. MODIS cloud determination has known error [25]. The influence of sub-pixel clouds may linger in a maximum value composite. For this reason, we also demonstrated a method to temporally smooth NDVI time-series data in order to improve data quality for applications including determining phenological characteristics and monitoring vegetation change where shorter composite periods are desirable [5,26-28]. An extra smoothing step was taken to demonstrate the value of temporal smoothing to reduce the effects of poor quality observations before using eMODIS data in operational applications. Figure 6 shows the zonal data results for 2011 Terra eMODIS prior to and after smoothing. The outlier data values in eMODIS were reduced as compared to the standard MODIS (Figure 6). Temporal smoothing minimized the apparent noise found in eMODIS and improved high value data consistency. Deviations from the 1:1 line implied overestimation of the smoothed eMODIS NDVI as compared to unsmoothed standard MODIS. Smoothing the data resulted in an overall increase in the NDVI data as subpixel influences were filtered and adjusted upward. However, for operational applications smoothing is typically applied consistently to the complete data record resulting in internally comparable data time series.

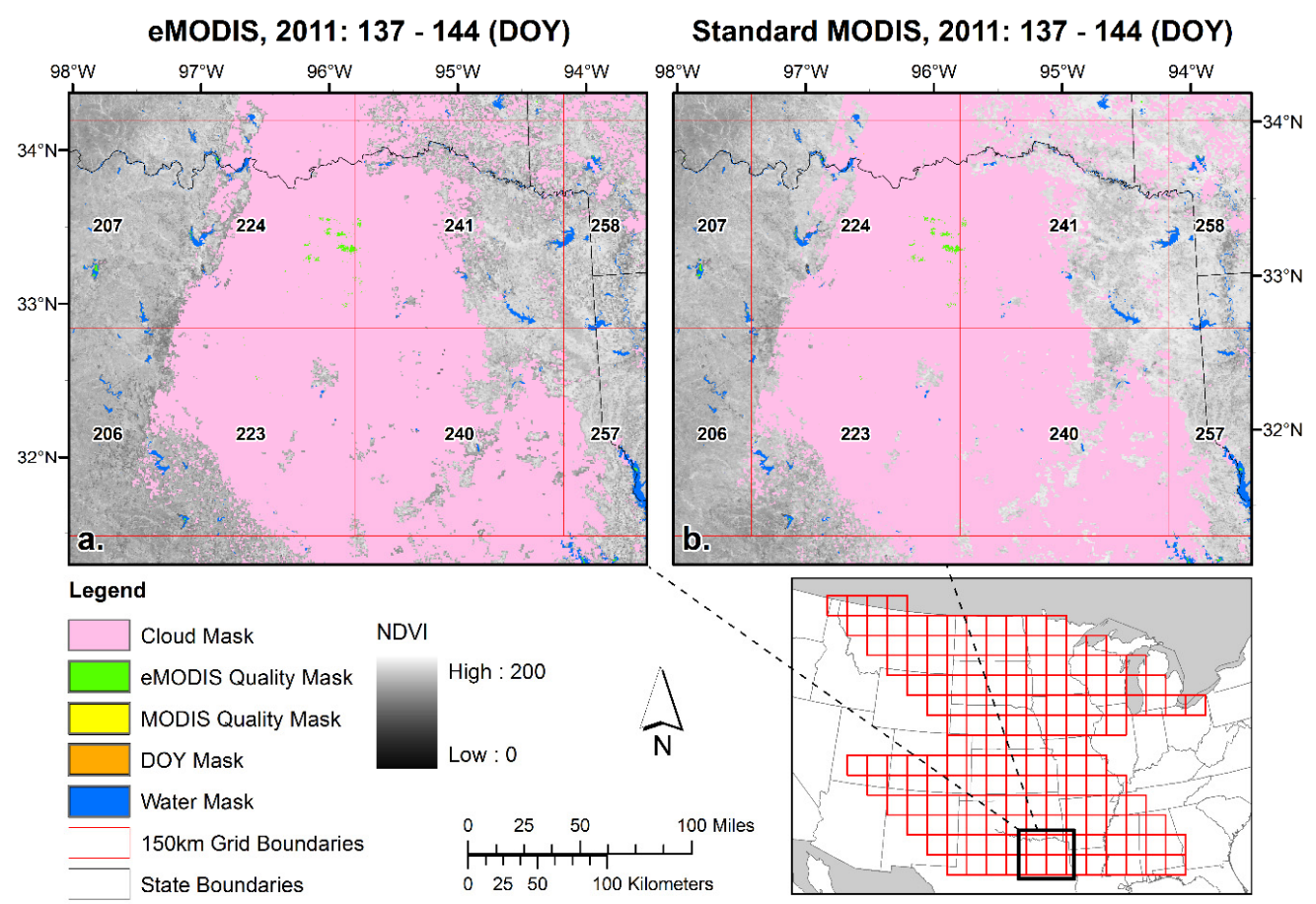

Figure 5. Close up of NDVI and mask values for (a) Terra eMODIS and (b) standard MODIS (MOD09Q1) for one composite period (doy 137-144, 2011). 

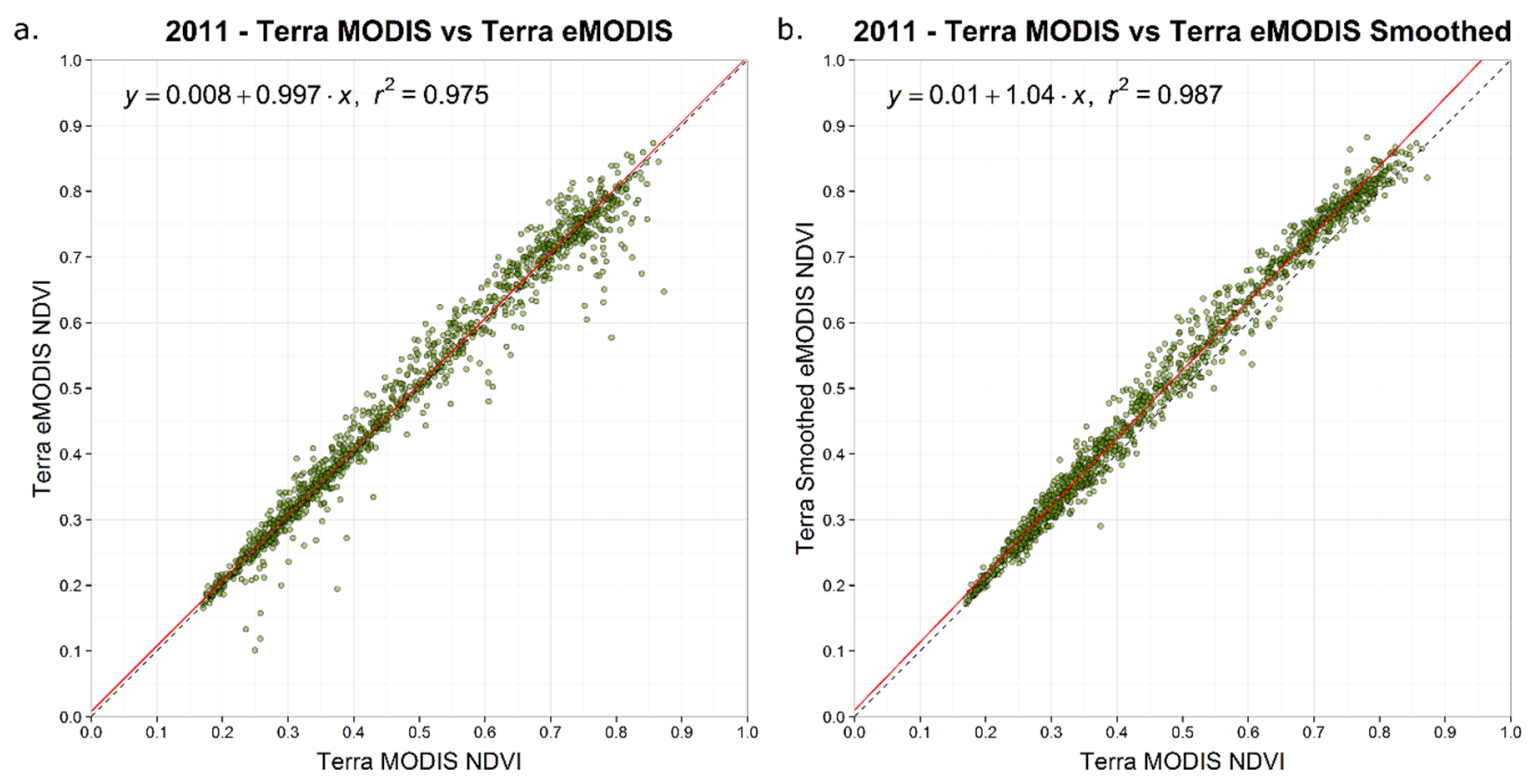

Figure 6. Scatter plots showing 2011 study zone NDVI (Standard Terra MODIS vs. Terra eMODIS) (a) without temporal smoothing and (b) with temporal smoothing.

\section{Conclusions}

This study evaluated a low-latency operational satellite data stream known as eMODIS through a comparison to high quality standard MODIS surface reflectance data. The eMODIS and standard MODIS data averaged over $150 \mathrm{~km}$ grid cells over 8years were used in this comparison. The results of this study indicated that eMODIS normalized difference vegetation index (NDVI), from both Aqua and Terra platforms, had a high level of agreement to standard MODIS NDVI (calculated from Collection 5 MOD09Q1 and MYD09Q1 surface reflectance) after data quality masks were applied to the data. Statistical agreement measures of the $\mathrm{r}^{2}$, agreement coefficient (AC), and root mean square deviation (RMSD) were 0.98, 0.98, and 0.03, respectively, for both Aqua and Terra eMODIS-standard MODIS data pairs. Slight differences in the mean values of the grid cells between the Aqua/Terra data pairs were only apparent at higher decimal places. Results indicated that the eMODIS source of application-ready monitoring image data provided comparable data quality to standard MODIS however the presence of outliers in the study suggested that eMODIS cloud and angle selection should be revisited. The statistical results of the study support confidence in the operational community, needing low latency observations and currently applying the eMODIS data to monitoring applications. We showed a temporal smoothing approach to reduce data noise related to cloud contamination in the seven-day eMODIS composites, demonstrating that rapid operational applications can still have access to good quality data. If better quality data are a higher priority than low latency data, users have the option of working with the standard MODIS products that are usually available more than 5 days after satellite overpass.

MODIS Collection 6 (C6), representing an implementation of revised processing algorithms in the forward stream as well as a reprocessing of the MODIS land and atmosphere global data archives, is now scheduled for full release in late 2015 or early 2016. Revised C6 calibration approaches will address sensor degradation related to the aging of the MODIS instruments on Terra and Aqua [29]. The $\mathrm{C} 5$ data stream will be maintained in tandem with $\mathrm{C} 6$ for a minimum of 1 year, which will allow the operational community to transition to C6 MODIS inputs for monitoring applications. Provided future stability in the eMODIS processing system and ready access to C6 input data sets, we assume a similar strong relationship between eMODIS and MODIS NDVI data in the C6 era that was shown in this study. As soon as the data are available, reprocessing of the eMODIS archive using historical C6 inputs is planned to address operational community requirements. 
Operational applications that rely on timely AVHRR and MODIS inputs are now facing an impending change in critical input data streams due to the upcoming end of the NOAA AVHRR-series and the over 15- and 13-year operational lives of Terra and Aqua MODIS, respectively. There is currently an operational AVHRR instrument aboard the METOP-A platform; however, operational data processing of these data has not yet been implemented by the USGS. Beyond the end of the MODIS era, whenever that should occur, is a necessary transition in operational monitoring systems to ingest input data from the VIIRS instrument. VIIRS was designed to provide Earth monitoring continuity from MODIS and AVHRR and is the logical follow-on to MODIS for operational applications because of the similarities in the spatial, geometric, and radiometric characteristics of VIIRS [30]. Future exploration and testing of VIIRS data in an operational data stream are planned.

Operational applications that rely on timely AVHRR and MODIS inputs are now facing an impending change in critical input data streams due to the upcoming end of the NOAA AVHRR-series and the over 15- and 13-year operational lives of Terra and Aqua MODIS, respectively. There is currently an operational AVHRR instrument aboard the METOP-A platform however operational data processing of these data has not yet been implemented by the USGS. Beyond the end of the MODIS era, whenever that should occur, is a necessary transition in operational monitoring systems to ingest input data from the VIIRS instrument. VIIRS was designed to provide Earth monitoring continuity from MODIS and AVHRR and is the logical follow-on to MODIS for operational applications because of the similarities in the spatial, geometric, and radiometric characteristics of VIIRS [30].

Acknowledgments: We gratefully acknowledge Calli Jenkerson, Gail Schmidt, and Thomas Maiersperger, who were instrumental in the development of the original eMODIS system. In addition, we are also grateful to the EROS Long Term Archive for continuing the operational control of the eMODIS system with funding from the USGS Land Remote Sensing Program. Thanks go to K. Gallo and three anonymous reviewers for providing insightful review comments. Any use of trade, firm, or product names is for descriptive purposes only and does not imply endorsement by the U.S. Government.

Author Contributions: All authors contributed significantly to this manuscript. Specific contributions include methodology (Jesslyn Brown, Danny Howard, Bruce Wylie, Lei Ji), data collection (Danny Howard), data analysis (Danny Howard, Aaron Friesz), and manuscript preparation (Jesslyn Brown, Danny Howard, Bruce Wylie, Carolyn Gacke, Aaron Friesz).

Conflicts of Interest: The authors declare no conflict of interest.

\section{References}

1. Atzberger, C. Advances in remote sensing of agriculture: Context description, existing operational monitoring systems and major information needs. Remote Sens. 2013, 5, 949-981. [CrossRef]

2. Davies, D.K.; Ilavajhala, S.; Wong, M.M.; Justice, C.O. Fire information for resource management system: Archiving and distributing MODIS active fire data. IEEE Trans. Geosci. Remote Sens. 2009, 47, 72-79. [CrossRef]

3. Hammer, D.; Kraft, R.; Wheeler, D. Alerts of forest disturbance from MODIS imagery. Int. J. Appl. Earth Obs. Geoinf. 2014, 33, 1-9. [CrossRef]

4. Vrieling, A.; Meroni, M.; Shee, A.; Mude, A.G.; Woodard, J.; de Bie, C.A.J.M.; Rembold, F. Historical extension of operational NDVI products for livestock insurance in Kenya. Int. J. Appl. Earth Obs. Geoinf. 2014, 28, 238-251. [CrossRef]

5. Brown, J.F.; Wardlow, B.; Tadesse, T.; Hayes, M.; Reed, B.C. The Vegetation Drought Response Index (VegDRI): A new integrated approach for monitoring drought stress in vegetation. GISci. Remote Sens. 2008, 45, 16-46. [CrossRef]

6. Hargrove, W.W.; Spruce, J.P.; Gasser, G.E.; Hoffman, F.M. Toward a national early warning system for forest disturbances using remotely sensed canopy phenology. Photogramm. Eng. Remote Sens. 2009, 1150-1156.

7. Carlson, J.D.; Burgan, R.E.; Engle, D.M.; Greenfield, J.R. The Oklahoma fire danger model: An operational tool for mesoscale fire danger rating in Oklahoma. Int. J. Wildland Fire 2002, 11, 183-191. [CrossRef] 
8. Townshend, J.R.G.; Justice, C. Towards operational monitoring of terrestrial systems by moderate-resolution remote sensing. Remote Sens. Environ. 2002, 83, 351-359. [CrossRef]

9. Xie, Y.; Xiong, X.; Qu, J.J.; Che, N.; Summers, M.E. Impact analysis of MODIS band-to-band registration on its measurements and science data products. Int. J. Remote Sens. 2011, 32, 4431-4444. [CrossRef]

10. Jenkerson, C.; Maiersperger, T.; Schmidt, G. eMODIS: A User-Friendly Data Source; Open-File Report 2010-1055; U.S. Geological Survey: Reston, VA, USA, 2010.

11. Eidenshink, J. A 16-year time series of $1 \mathrm{~km}$ AVHRR satellite data of the conterminous United States and Alaska. Photogramm. Eng. Remote Sens. 2006, 72, 1027-1035. [CrossRef]

12. Ji, L.; Wylie, B.; Ramachandran, B.; Jenkerson, C. A comparative analysis of three different MODIS NDVI datasets for Alaska and adjacent Canada. Can. J. Remote Sens. 2010, 36, S149-S167. [CrossRef]

13. Verbyla, D. Comparison of eMODIS and MOD/MYD13A2 NDVI products during 2012-2014 spring green-up periods in Alaska and northwest Canada. Int. J. Appl. Earth Obs. Geoinf. 2014, 36, 83-86. [CrossRef]

14. Vermote, E.F.; El Saleous, N.Z.; Justice, C.O. Atmospheric correction of MODIS data in the visible to middle infrared: First results. Remote Sens. Environ. 2002, 83, 97-111. [CrossRef]

15. Vermote, E.F.; Kotchenova, S.Y.; Ray, J.P. MODIS Surface Reflectance User's Guide, Version 1.3; MODIS Land Surface Reflectance Science Computing Facility: Greenbelt, MD, USA, 2011.

16. Jönsson, P.; Eklundh, L. Seasonality extraction by function fitting to time-series of satellite sensor data. IEEE Trans. Geosci. Remote Sens. 2002, 40, 1824-1832. [CrossRef]

17. Chen, J.; Jönsson, P.; Tamura, M.; Gu, Z.; Matsushita, B.; Eklundh, L. A simple method for reconstructing a high-quality NDVI time-series data set based on the Savitzky-Golay filter. Remote Sens. Environ. 2004, 91, 332-344. [CrossRef]

18. Swets, D.L.; Reed, B.; Rowland, J.R.; Marko, S.E. A weighted least-squares approach to temporal smoothing of NDVI. In Proceedings of the 1999 ASPRS Annual Conference: From Image to Information, Portland, OR, USA, 17-21 May 1999.

19. Funk, C.; Budde, M. Phenologically-tuned MODIS NDVI-based production anomaly estimates for Zimbabwe. Remote Sens. Environ. 2009, 113, 115-125. [CrossRef]

20. Boyte, S.P.; Wylie, B.K.; Major, D.J.; Brown, J.F. The integration of geophysical and enhanced moderate resolution imaging spectroradiometer normalized difference vegetation index data into a rule-based, piecewise regression-tree model to estimate cheatgrass beginning of spring growth. Int. J. Digit. Earth 2015, 8, 116-130. [CrossRef]

21. Reed, B.C.; Brown, J.F.; VanderZee, D.; Loveland, T.R.; Merchant, J.W.; Ohlen, D.O. Measuring phenological variability from satellite imagery. J. Veg. Sci. 1994, 5, 703-714. [CrossRef]

22. Wylie, B.K.; Fosnight, E.A.; Gilmanov, T.G.; Frank, A.B.; Morgan, J.A.; Haferkamp, M.R.; Meyers, T.P. Adaptive data-driven models for estimating carbon fluxes in the Northern Great Plains. Remote Sens. Environ. 2007, 106, 399-413. [CrossRef]

23. Wylie, B.K.; Zhang, L.; Bliss, N.; Ji, L.; Tieszen, L.L.; Jolly, W.M. Integrating modelling and remote sensing to identify ecosystem performance anomalies in the boreal forest, Yukon River Basin, Alaska. Int. J. Digit. Earth 2008, 1, 196-220. [CrossRef]

24. Whitcraft, A.K.; Vermote, E.F.; Becker-Reshef, I.; Justice, C.O. Cloud cover throughout the agricultural growing season: Impacts on passive optical earth observations. Remote Sens. Environ. 2015, 156, $438-447$. [CrossRef]

25. Wilson, A.M.; Parmentier, B.; Jetz, W. Systematic land cover bias in Collection 5 MODIS cloud mask and derived products-A global overview. Remote Sens. Environ. 2014, 141, 149-154. [CrossRef]

26. Gu, Y.; Brown, J.; Miura, T.; van Leeuwen, W.J.; Reed, B. Phenological classification of the United States: A geographic framework for extending multi-sensor time-series data. Remote Sens. 2010, 2, 526-544. [CrossRef]

27. Kimball, J.S.; McDonald, K.C.; Zhao, M. Spring thaw and its effect on terrestrial vegetation productivity in the Western Arctic observed from satellite microwave and optical remote sensing. Earth Interact. 2006, 10, 1-22. [CrossRef]

28. Wang, C.; Cao, R.; Chen, J.; Rao, Y.; Tang, Y. Temperature sensitivity of spring vegetation phenology correlates to within-spring warming speed over the Northern Hemisphere. Ecol. Indic. 2015, 50, 62-68. [CrossRef] 
29. Wang, D.; Morton, D.C.; Masek, J.; Wu, A.; Nagol, J.; Xiong, X.; Levy, R.; Vermote, E.; Wolfe, R.E. Impact of sensor degradation on the MODIS NDVI time series. Remote Sens. Environ. 2012, 119, 55-61. [CrossRef]

30. Justice, C.O.; Román, M.O.; Csiszar, I.; Vermote, E.F.; Wolfe, R.E.; Hook, S.J.; Friedl, M.; Wang, Z.; Schaaf, C.B.; Miura, T.; et al. Land and cryosphere products from Suomi NPP VIIRS: Overview and status. J. Geophys. Res. Atmos. 2013, 118, 9753-9765. [CrossRef] [PubMed]

(C) 2015 by the authors; licensee MDPI, Basel, Switzerland. This article is an open access article distributed under the terms and conditions of the Creative Commons by Attribution (CC-BY) license (http:/ / creativecommons.org/licenses/by/4.0/). 